\title{
Development status and Countermeasures of renewable energy in China
}

\author{
XueBin $\mathrm{Hu}^{1 *}$ \\ ${ }^{1}$ Wuhan University of Science and Technology, Wuhan, China
}

\begin{abstract}
This paper studies the development status of renewable energy in China. In this field, there are some problems in China, such as imperfect legal and policy system, insufficient market operation, weak public awareness of environmental protection, imperfect scientific research system and so on. At the end of the paper, the corresponding improvement measures are put forward.
\end{abstract}

\section{Introduction}

Since the deterioration of the earth's environment, renewable energy has been gradually concerned by countries all over the world, especially the healthy development of economy brought by renewable energy and its positive role in maintaining the ecological environment. The latest data showed that China, the United States and the European Union account for more than half of the world's total greenhouse gas emissions, which are the three largest countries in the world. Global greenhouse gas concentrations continue to reach new highs, which will lead to increasingly serious climate change in the future. In view of this phenomenon, based on the development concept of the community of human destiny, it is one of the important tasks for China to carry the construction of ecological civilization forward establish and improve the ecological economic system of green, low-carbon and circular development. Therefore, China urgently needs to develop low-carbon economy, save energy and reduce the emission of environmental hazards. This requires full play to the competitive advantage of renewable energy, giving priority to development and utilization of renewable energy. China has proposed the overall goal of renewable energy development and the development goals of hydraulic power, solar energy, wind energy, ocean energy, etc In order to achieve the above goals, we need to deeply analyze the present condition of China's energy development and the development of renewable energy. Through the understanding of the actual situation, the paper analyzes the problems existing in the development of renewable energy, and puts forward corresponding suggestions.

\section{Present condition of energy development in China}

In early 2020, COVID-19 broke out in China. This public health emergency has caused a huge impact on China's economy and society. With the gradual improvement of the epidemic situation and the gradual control of the problem, the domestic economy is also improving under the implementation of the macro cycle policy, and the development trend is good. In the meantime, the development of China's energy industry is back on track, coal consumption continues to pick up, oil and gas imports increase, and electric power load continues to reach a new high. The energy structure has been continuously optimized, and all indicators have returned to a positive year-on-year growth.

With the rapid control of COVID-19, China's economic development and society are gradually on the right track, and the demand for energy is also gradually increasing. According to preliminary calculation, China's total annual energy consumption increased by $2.2 \%$ over the previous year, reaching 4.97 billion tons of standard coal. The change trend reflects that China's economic recovery is obvious. According to the relevant survey data, the growth of natural gas consumption is the largest, reaching $7.2 \%$, while the growth of coal is the smallest, only $0.6 \%$. Crude oil and electricity consumption increased by $3.3 \%$ and $3.1 \%$ respectively. The relevant data is shown in Figure 1.

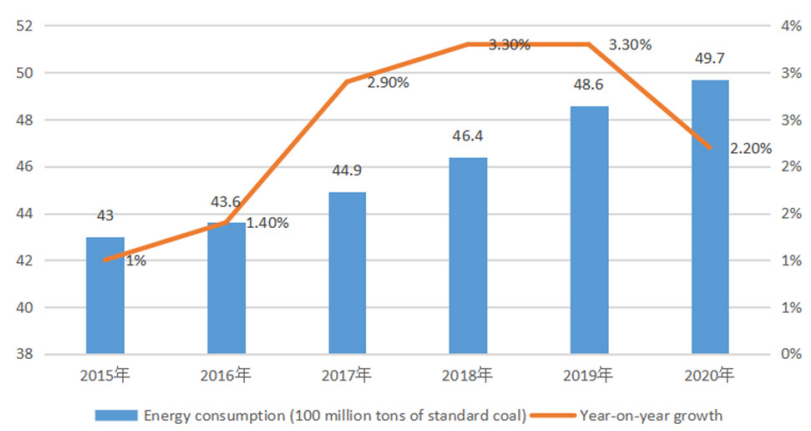

Figure 1. China's total energy consumption and year-on-year growth in 2015-2020

Statistics from the National Energy Administration show that coal consumption accounts for half of the total

\footnotetext{
* Corresponding author: huxuebin97@126.com
} 
energy consumption, up to $56.8 \%$, but it has decreased by $0.9 \%$ compared with last year. The total clean energy consumption has increased by $1.0 \%$ compared with last year, accounting for $24.4 \%$ of the total energy consumption, including renewable energy sources such as hydraulic power and wind power. From 2010 to 2020, the proportion of coal consumption in China's total energy consumption decreased from $69.2 \%$ to $56.7 \%$, a decrease of $12.5 \%$; The proportion of clean energy (including renewable energy) consumption in total energy consumption increased from $13.4 \%$ to $24.4 \%$, with an increase of $11 \%$. The energy consumption structure continued to change to green and low-carbon. Relevant data are shown in Figure 2. If the proportion of clean energy consumption is to reach the targets of $25 \%$ by 2020 and $35 \%$ by 2030 , efforts from all sectors will need to be redoubled.

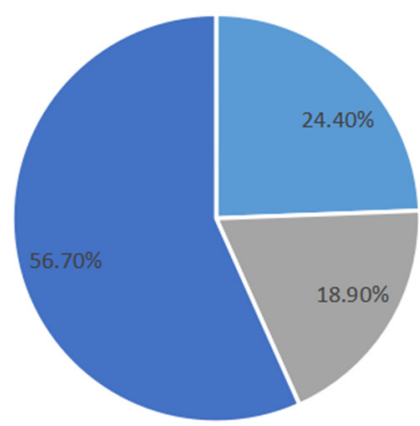

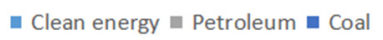

Figure 2. China's energy consumption structure in 2020

\section{Development status of renewable energy in China}

\subsection{China's renewable energy policy orientation}

In terms of fiscal policy, China's renewable energy law issued in 2006 has made relevant provisions on the on grid electricity price, strengthened policy coordination, and focused on strengthening policy support for renewable energy land and sea use, finance, taxation, investment and financing, so as to promote sustainable and healthy development and high-quality development of renewable energy.

In terms of market mechanism, China has actively implemented the "green certificate trading mechanism" by learning from other developed countries, which further improves the marketization degree of China's renewable energy industry, improves the full guarantee purchase system of renewable energy, links up with marketoriented trading, and encourages renewable energy to participate in the market orderly, so as to realize full consumption.

On the development goal of renewable energy, the national strategic positioning order of renewable energy is from alternative energy to mainstream energy to leading energy. The strategy can be realized in three time points, that is, renewable energy accounts for $15 \%$ of energy consumption in 2020 and about $25 \%$ in 2030 . By 2050 , renewable energy, as the leading energy, should account for about $40 \%$ of energy consumption.

Renewable energy policy mainly includes administrative policy and market policy. At present, in the heyday of renewable energy development, China mainly uses administrative means to promote the development of renewable energy, including the implementation of various key projects, financial subsidies and tax policies. China's renewable energy has developed rapidly in recent years, which can be said to achieve leapfrog development.

\subsection{Technology orientation of renewable energy in China}

In 2020, the energy data report released by the China Federation of electric power enterprises shows that, from the perspective of power structure, renewable energy power generation will reach 2045.54 billion kilowatt hour, with a year-on-year increase of about 176.1 billion kilowatt hour. Of the total power generation, renewable energy generation accounted for $27.7 \%$, up $1 \%$ year on year. China's non fossil energy power generation increased by $10.7 \%$ over last year, reaching 2393.8 billion kilowatt hour, accounting for $32.6 \%$ of China's power generation, an increase of 1.7 percentage points over the previous year, and the power supply capacity of non fossil energy continued to increase. As shown in Figure 3, excluding thermal power, in other words, the main technical paths of renewable energy in China are hydraulic power, wind power and solar photovoltaic.

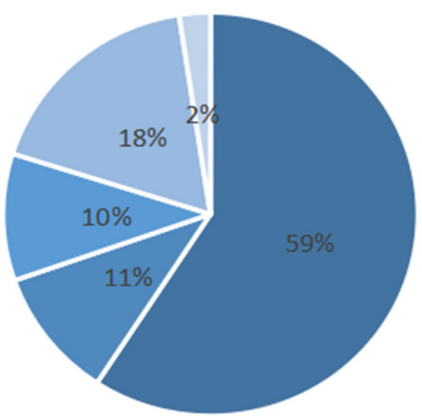

$$
\begin{aligned}
& \text { - Thermal-electricity } \square \text { Wind power } \\
& \square \text { Hydropower }
\end{aligned}
$$

Figure 3. China's power supply structure in 2019

In terms of hydraulic power generation, China's hydraulic power technology has already entered the international advanced ranks, and even exceeded the international level in some aspects. China has become the largest hydraulic power country in the world in 2019, because according to statistics, by the end of 2019, China's annual hydraulic power generation will exceed 1 trillion watt hours, and the total installed capacity of hydraulic power will be about 356 million kilowatts. In fact, as early as 2015, China's total installed hydraulic power capacity has reached 320 million kilowatt hour. In hydraulic power, China mainly uses three-dimensional geological modeling technology, honeycomb hydraulic power technology, hydraulic power automation technology and hydro pneumatic power generation 
technology. At present, China will continue to develop intelligent hydraulic power technology.

Photothermal power generation and photovoltaic power generation are the main forms of photovoltaic power generation. At present, China has a large scale of photovoltaic power. According to the statistics of the national energy administration, by the end of June 2019, the installed capacity of centralized photovoltaic power generation in China has increased by $6.82 \mathrm{gw}$, a year-onyear increase of $16 \%$, reaching $130.58 \mathrm{gw}$, while the installed capacity of distributed photovoltaic power generation has increased by $4.58 \mathrm{gw}$, a year-on-year increase of $31 \%$, reaching $55.02 \mathrm{gw}$. The total installed capacity of photovoltaic power generation in China has reached $185.59 \mathrm{gw}$.

Installed capacity (10000 kW)

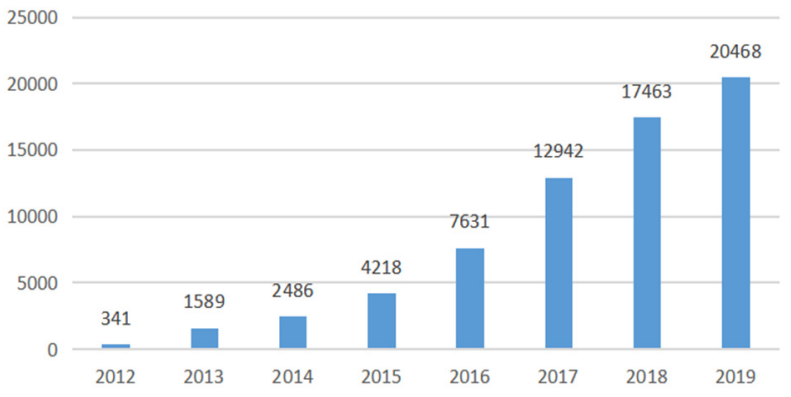

Figure 4. Cumulative installed capacity of solar power generation in China

Compared with photovoltaic power generation, wind power generation has experienced a phased development in China. Since the promulgation of the renewable energy law in 2006, China's wind power has entered the stage of large-scale development and application. However, after several years of development, China has appeared the imagination of abandoning wind power and limiting power. It was not until 2015, when the benchmark price of wind power was lowered, that China entered the wind power industry again, and the scale of new installed capacity was obvious. According to statistics, China's total installed capacity of wind power in 2019 is 21.05 million kilowatts..

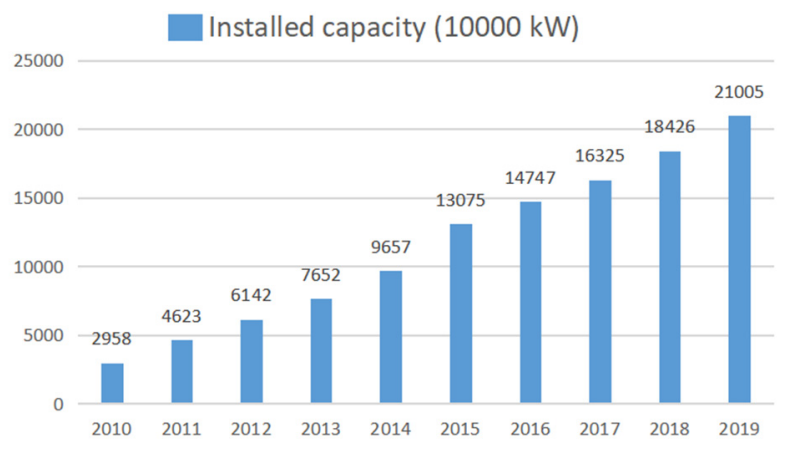

Figure 5. Cumulative installed capacity of wind power in China

\section{Problems in the development of renewable energy in China}

\subsection{The system of renewable energy related laws and policies is not perfect}

It was not until 2006 that China promulgated and implemented the renewable energy law, which stipulated the responsibilities and obligations of the Chinese government and society, providing a reliable legal guarantee for the development of renewable energy. However, in terms of content, the bill covers less renewable energy and is too broad. It was only amended in 2009 and lacks comprehensive, in-depth and detailed design of laws and policies. This leads to the low operability of the current law, because the laws and policies are not comprehensive, and the system stipulates the responsibilities and obligations of all stakeholders, which leads to the governments' unwillingness to accept foreign renewable power due to interest problems, and thus leads to the aggravation of power rationing situation. In a word, the incompatibility of relevant laws and policies leads to many contradictions in the development of renewable energy.

\subsection{Market operation is insufficient, market allocation is not obvious}

At present, the use stage of renewable energy industry in China still does not reflect the commercialization nature, and the market role is not obvious. And due to the lack of stable market security policy to guide the development of renewable energy market in China, the lack of incentives leads to weak innovation ability and slow technological development. Although the state has invested a lot of funds to increase its support for renewable energy, its development in practice is still under the control of other countries, and the main reason is the lack of core technology., It is necessary to strengthen the marketoriented operation of renewable energy in China and play the role of market allocation.

\subsection{Public awareness of environmental protection is weak}

The majority of the public in China still stay in the understanding of China's vast territory and abundant energy resources, and the awareness of environmental protection is weak, which leads to the low participation of the public in the consumption of renewable energy, and the whole society has not yet formed a comprehensive renewable energy development atmosphere. This requires the government to continuously publicize the current situation of energy shortage and the development advantages of renewable energy, and improve citizens' awareness of consuming such energy products. Only in this way can we expand the application of renewable energy and accelerate the development of renewable energy output. 


\subsection{The research system of renewable energy is not perfect}

Although the state continues to invest a lot of money in the development of renewable energy industry, improve the support for the energy. But from the current situation, the funds are still very scarce. If we want to increase the development potential of renewable energy in China, we must supplement it with efficient financing mechanism and market support. Otherwise, insufficient R \& D investment will inevitably lead to poor independent innovation ability and less $\mathrm{R} \& \mathrm{D}$ reserves. The imperfection of renewable energy research system in China also makes it difficult to apply innovative achievements to reality.

\section{Suggestions}

\subsection{Improve the system of renewable energy related laws and policies}

We should speed up the pace of Amending China's renewable energy law, establish the legal status of renewable energy development according to the actual needs, improve its utilization proportion in the overall energy structure, and establish administrative authority. According to the development of renewable energy in various regions, problems can be found in the process of continuous development, and relevant policies and regulations can be improved to improve the operability of policies and regulations. Secondly, coordinate the direct relationship between renewable energy laws and policies and other energy development policies, maintain the continuity and consistency of relevant laws and policies, and jointly promote the sustainable development of renewable energy industry.

\subsection{Speed up market operation and industrialization}

Relevant government departments should strengthen the development planning of renewable energy in China. In other words, it is necessary to strengthen leadership, actively broaden financing channels in accordance with the requirements of industrial development planning, so as to support the rapid development of renewable energy industry. We should establish the corresponding market mechanism to cooperate with the government's planning, increase the development of the renewable energy market, give full play to the main role of the market, and support the renewable energy enterprises to develop the market by means of preferential policies and tax incentives, so as to operate well under the market mechanism. At the same time, we should actively cultivate and standardize the market and intervene selectively.

\subsection{Enhance public awareness of environmental protection}

The government should strengthen the publicity and information dissemination of environmental protection development and renewable energy. We should make full use of all kinds of publicity and take various publicity forms to improve the public's awareness of renewable energy and make them realize the importance of renewable energy construction. By playing the main role of the people, we can enhance the development atmosphere of renewable energy in China. Secondly, the relevant departments and personnel engaged in the development of renewable energy should be trained regularly to strengthen exchanges. Through the establishment of national and regional renewable energy information websites, the healthy and rapid development of the industry should be guided.

\subsection{Increase investment in renewable energy innovation}

The first is capital investment, followed by talent investment and international exchanges and cooperation. We should focus on the problems in the development of renewable energy in China and establish a national renewable energy research center. We will strengthen the training of high-end talents. Secondly, we should extensively carry out international exchanges and cooperation, focus on and use China, and purposefully introduce, digest and absorb foreign advanced technologies, processes and key equipment. Enterprises, universities and scientific research institutions are encouraged to carry out the combination of production and research, so as to speed up the related scientific and technological development, accelerate the transformation of its achievements, promote the improvement of the overall technology and equipment level of the industry, and develop China's renewable energy industry better and faster.

\section{References}

1. China Electric Power Enterprise Federation. 2020 national electric power industry statistics express [R]. 2021

2. Huang Bo, Xu Wenyong, Wang Quanhui, et al. Reference and Enlightenment of renewable energy development in Germany [J]. China biogas, 2021,39 (1):45-53.Doi:10.3969/j.issn.10001166.2021.01.008

3. ZENG MING, LIU XIMEI, LI YULONG, et al. Review of renewable energy investment and financing in China: Status, mode, issues and countermeasures $[\mathrm{J}]$. Renewable \& sustainable energy reviews,2014,31(Mar.):23-37.

4. China Coal Industry Association. 2020 annual report on coal industry development [R]. 2021

5. Shi Jingli. Supporting mechanism of international renewable energy participation in power market and Its Enlightenment to China [J]. China energy, 2021,43 (3): 55-58. 